\title{
Management of Water Resources in a Hyper-Arid Area: Strategy and Issues (Case of Oued-Souf Valley-South Eastern of Algeria)
}

\author{
Salim Khechana ${ }^{1,2}$, El-Fadel Derradji ${ }^{1}$ \\ ${ }^{1}$ Laboratory of Geology, Badji Mokhtar University, Annaba, Algeria \\ ${ }^{2}$ Faculty of Sciences and Technology, Hydraulic Department, El Oued University, El Oued, Algeria \\ Email: khechana_salim@yahoo.fr
}

Received July 3, 2012; revised September 5, 2012; accepted October 15, 2012

\begin{abstract}
Rising Groundwater in Oued-Souf valley is result to errors committed by human in their interventions on the ecosystems and the mismanagement of this resource, witch principally marked in overexploitation of depth groundwater and the used sewerage system, leading the region to a truly dramatic and almost desperate, palms were turned into sort of marshes, where reeds take the place of dead palm trees. This situation lead us to search a model of water resources management, according to sustainability criteria taking into account the socio-economic (social, agricultural, industrial, tourism $\cdots$ ) and ecosystem aspects (environmental and territorial). This by adapting and implementing the Integrated Management of Water Resources (IMWR) in this unit of water resources, so as to guide and mobilize progressively human, informational, financial and material resources, as well as the various sectors private and public to research concrete and measurable results, for water and ecosystems those are associated and that people wanted to see protected and restored.
\end{abstract}

Keywords: Rising Groundwater; Oued-Souf Valley; Integrated Management of Water Resources; Confrontation Resources-Needs

\section{Introduction}

The adoption of Integrated Management of Water Resources (IMRW) has the direct effect of human being: material, financial and informational. It can realize different aims of various sectors and reach permanent solution which wondering by regions' people.

Therefore, each country applies it, on the one hand, by using the nature and intensity of problems related to water, human being resources, institutional capacities, strengths and characteristics of the water actors, on the other hand by using cultural and natural landscape conditions [1].

The current water situation in the region of Oued Souf allow us to adapt this method of management in order to develop water resources, according to durable criteria and it will take as consideration the different aspects: agricultural, social, environmental, industrial and tourism.

\section{Presntation of the Study Area}

\subsection{Location}

Oued-Souf valley is unit of water resources located in the south-eastern of Algeria (Figure 1), in the center of a large synclinal basin, it is known as low-lying-Sahara because of the low altitude. It is occupying an area of $11,738 \mathrm{~km}^{2}$.

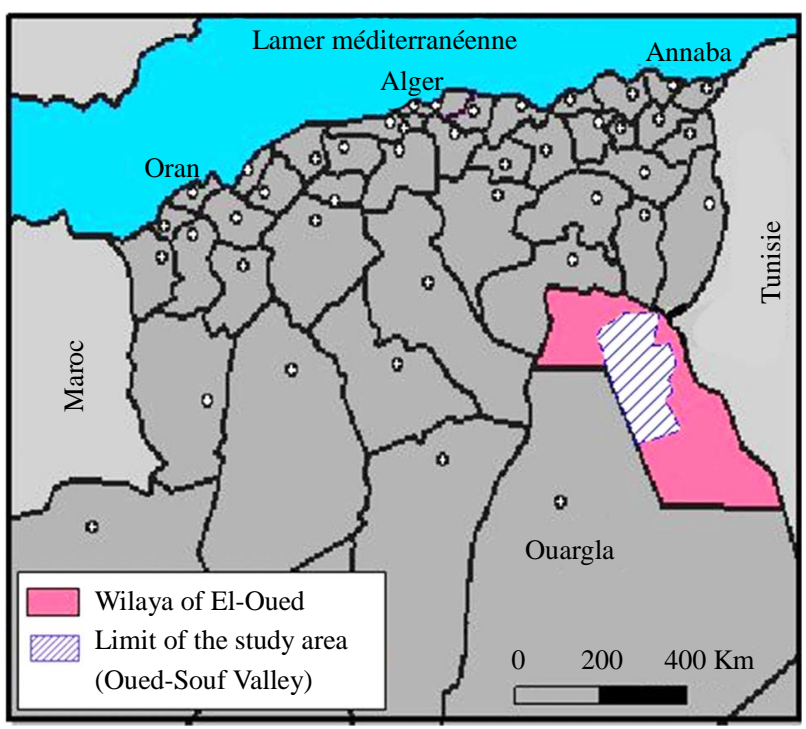

Figure 1. Location of study area. 
Representing administratively 18 municipalities and includes over 500 thousand inhabitants on 2009.

El Oued: known by municipality of thousand domes (the name is given because of the shape of houses); it is also characterized by the production of dates.

It is bounded by the following Lambert coordinates system the following Lambert coordinates system:

- $X=275,200 / 322,000$

- $\mathrm{Y}=3,665,000 / 3,743,000$

\subsection{Overview Climate}

The climate of study area is: hyper-arid Saharan-type that is in some points similar to the rest of the Sahara: hot and dry in summer, pretty cold in winter (from $2^{\circ} \mathrm{C}$ to $8^{\circ} \mathrm{C}$ ). It can be frost at night. In fact, the differences of temperature between day and night are very high (up to $30^{\circ} \mathrm{C}$ in summer). The annual average of temperature is $22.23^{\circ} \mathrm{C}$, the precipitation is about $73.97 \mathrm{~mm}$, witch totally con- tributing to the evaporation. The reserve is exhausted during the year. The sunstroke is very high (average of 351.4 hours) which results an excessive evaporation power [2].

The synthesis of climatic data allows us to draw the Ombrothermic diagram according the data coming from "Guemar weather station" during the period from 1978 to 2008 (Figure 2). It shows clearly that the hydrologic year of the region is characterized only by a dry period and the total absence of the wet period, even on January which is marked by the lowest temperature $\left(10.67^{\circ} \mathrm{C}\right)$ and the highest precipitation (14.65 mm).

\subsection{Diagnosis of Water Resources}

Oued-Souf valley has a very important water reserves, in the form of three aquifers: The Continental Intercalaire aquifer (CI), The Complex Terminal Aquifer (CT) and the Phreatic Aquifer [3]. Table 1 summarizes the aquifer systems in the region of El-Oued [4].

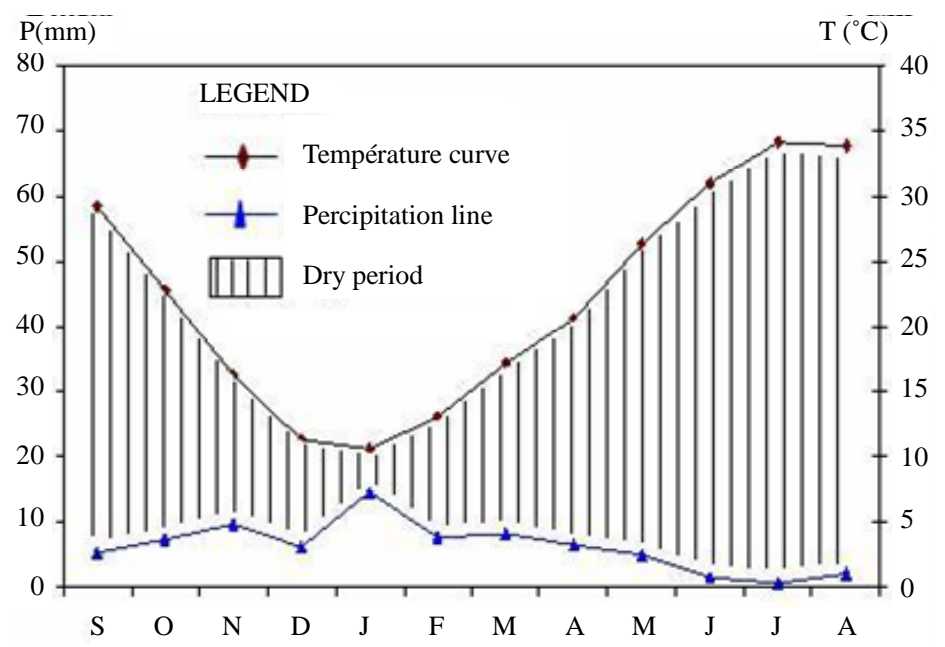

Figure 2. Ombrothermic diagram of Guemar station (El-Oued) during the period (1978-2008).

Table 1. Summary of aquifer systems in the region of El-Oued.

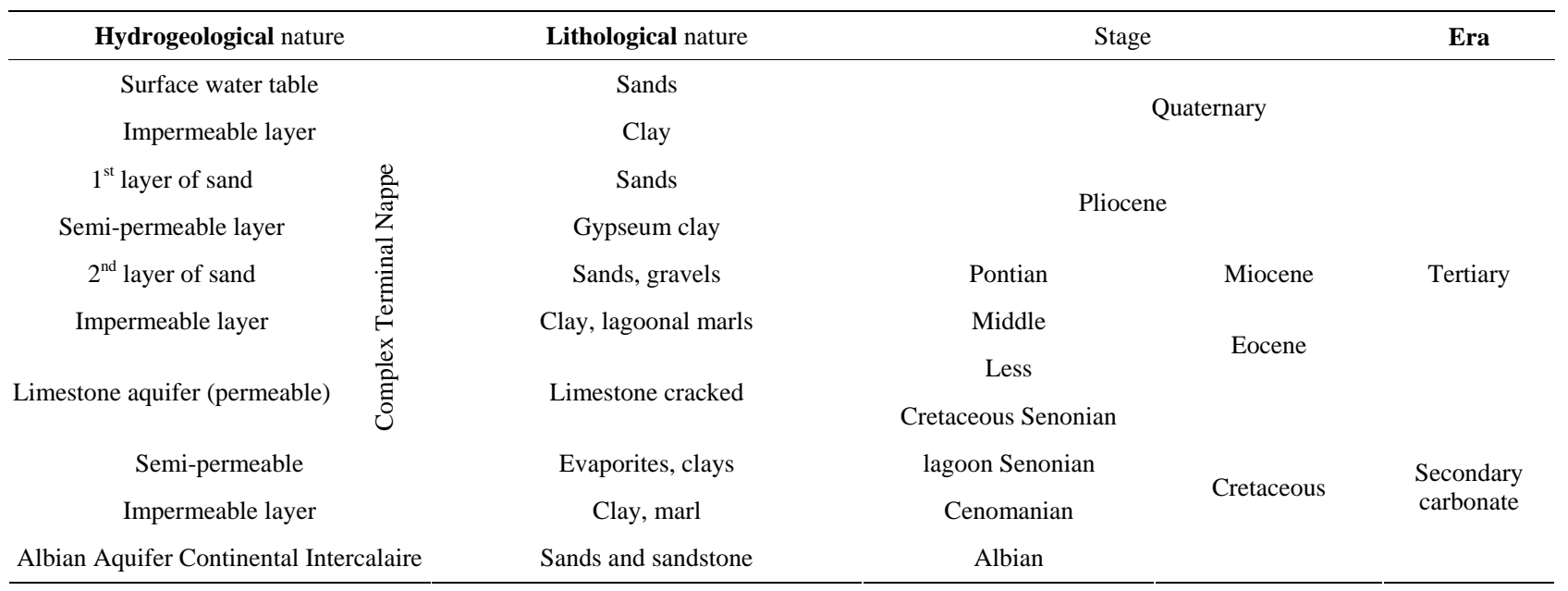




\section{Confrontation Resources/Needs of Water}

The approach that we adopted enables to:

- Evaluate resources and water needs over an observation period from 2002 to 2009 (8 years) for different sectors;

- Confrontation between the quantities of water requested and the real water provided for all users;

- Imagine possible scenarios in the short, medium and long term;

- Discussion of results, adapting a new strategy of management, and suggest some measures and adequate development [5].

\subsection{Water Resources}

The potential of groundwater resources established by the Hydraulics Direction of El-Oued (6) is as follows:

- Groundwater: $0.13 \times 10^{-6}$ billion $\mathrm{hm}^{3}$.

- Groundwater deep: 4.90 billion $\mathrm{hm}^{3}$ (2.7 billion $\mathrm{hm}^{3}$ from the CT and 2.2 billion $\mathrm{hm}^{3}$ from the CI).

Total: 4.90 billion $\mathrm{hm}^{3}$.

The mobilization of groundwater is $470 \mathrm{hm}^{3}$ per year throughout the region, but only $405.08 \mathrm{hm}^{3}$ are actually used (or $86.19 \%$ of mobilized resources).

The division of mobilized resources has objective to satisfy the needs of different users which are reported in Figure 3.

\subsection{Assembling Resources/Needs Data}

In Figure 4, we drew the various diagrams (mobilizing resources/exploitable resources/needs) in the same graph in order to demonstrate the speed of change in these parameters during those years (from 2002 to 2009).

\subsection{Forecast}

The planning of economic strategy and durable development requests on actual hydraulic information resource and especially on future expectation of consummation. We built the evolution scenarios on the hypothesis of continuity of tendency in recent years [6]. The forecast results are summarized in Table 2.

\subsection{Discussion and Interpretation of Results}

The obtained results are explained that the balance resources/needs water, is excess even in the long term (2040), and the growing needs will be offset by the volume of exploitable water.

But the nature of fossil groundwater in the region cause the problem of durability of their exploitation, more than that, this region considered as water area and the irrigated surface has more than doubled in 30 years reaching 150,944 hectares in 2040.

According to results in Table 2, the balance will remain positive (exploitable volume is greater than request) but we need a future management of water resources in the region that will arise again in terms of supply man-

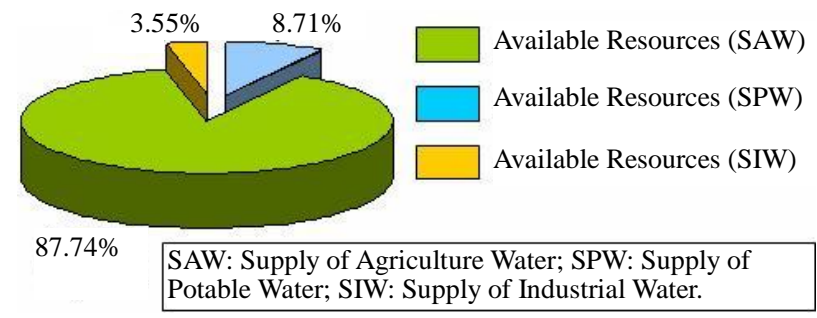

Figure 3. Representation of resources mobilized for three major consumers.

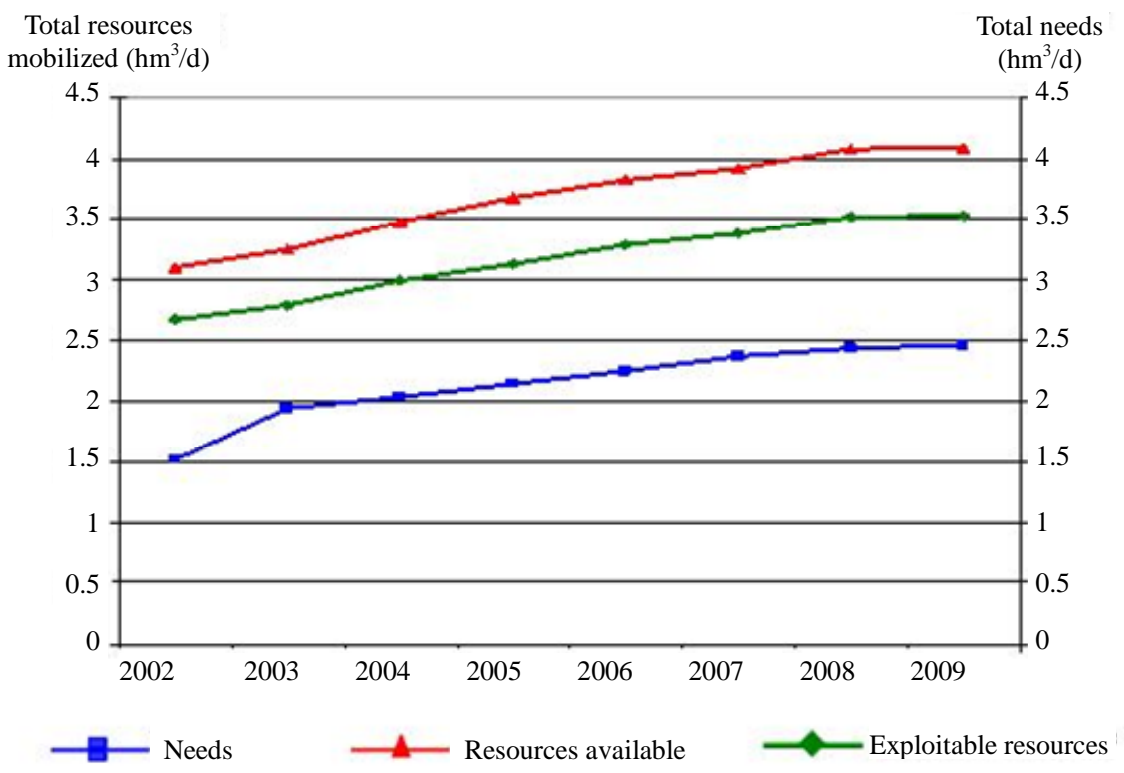

Figure 4. Confrontation resources-needs of different users of water. 
Table 2. Summary of results obtained by the forecast.

\begin{tabular}{|c|c|c|c|c|c|c|}
\hline Number of scenario & Population & $\begin{array}{l}\text { Irrigated area } \\
\text { (ha) }\end{array}$ & $\begin{array}{l}\text { Needs of supply water } \\
\left.\text { potable (hm }{ }^{3} / \text { year }\right)\end{array}$ & $\begin{array}{l}\text { Needs of supply water } \\
\text { agriculture (hm³/year) }\end{array}$ & $\begin{array}{l}\text { Needs of supply water } \\
\text { industrial (hm } \text { (h) } / \text { year) }^{-}\end{array}$ & $\begin{array}{l}\text { Total needs } \\
\left(\mathrm{hm}^{3} / \text { year }\right)\end{array}$ \\
\hline Scenario 0 (2009) & 486,170 & 59,935 & 46.10 & 983.02 & 14.51 & 1043.63 \\
\hline Scenario 01 (2015) & 582,883 & 76,999 & 56.42 & 1263.50 & 16.34 & 1336.26 \\
\hline Scenario 02 (2025) & 788,687 & 10,725 & 76.34 & 1760.00 & 24.60 & 1860.94 \\
\hline Scenario 03 (2040) & $1,241,334$ & 150,944 & 96.27 & 2480.00 & 34.60 & 2610.87 \\
\hline
\end{tabular}

agement in general, and efficiency irrigation in particular.

\section{Adaptation of the Integrated Management of Water Resources}

\subsection{First Steps: Towards a Rational Management of Water Resources}

From 2001, at the community level, local officials has taken concrete steps, some of these measures are:

- Reduce timing of potable water supply (2 hours/24 hours for each city, instead of 24 hours/24 hours);

- The creation of new wells in the groundwater for agriculture;

- Stopping execution of new wells for irrigation in the depth aquifers (the Continental Intercalaire Aquifer and Terminal Complex Aquifer);

- Development of agricultural areas irrigated from groundwater: the development of farms irrigated from ground water in affected areas has an important role to stabilize or reverse the rising water, this exploitation reject on the atmosphere about 10,000 to 15,000 $\mathrm{m}^{3}$ of water/hec per year.

- The development of new agricultural areas (irrigated by modern methods as drop by drop) has a remarkable positive impact by a stabilization or decline of water table in areas affected as example: nearby of El-Oued University (Photo 1).

- Filling of Ghouts: to fill the "Ghouts" flooded is not efficiency way to avoid or resolve the phenomenon of rising water, but can limit the proliferation of mosquitoes and the discharge in urban areas. It prevents water from to charge with salts by evaporation [7].

Photo 2 shows a Ghouts which was recently filled by the authorities after days of contamination of the rising.

In these steps, we noted, that these measures were not able to apply only with the collaboration of citizens and city's associations in the implementation of decisions that has been taken.

\subsection{Planning of a Mega-Project with Various Aspects}

Since 2005, the valley of Oued-Souf has received a great project for sewerage and drainage of wastewater, residual

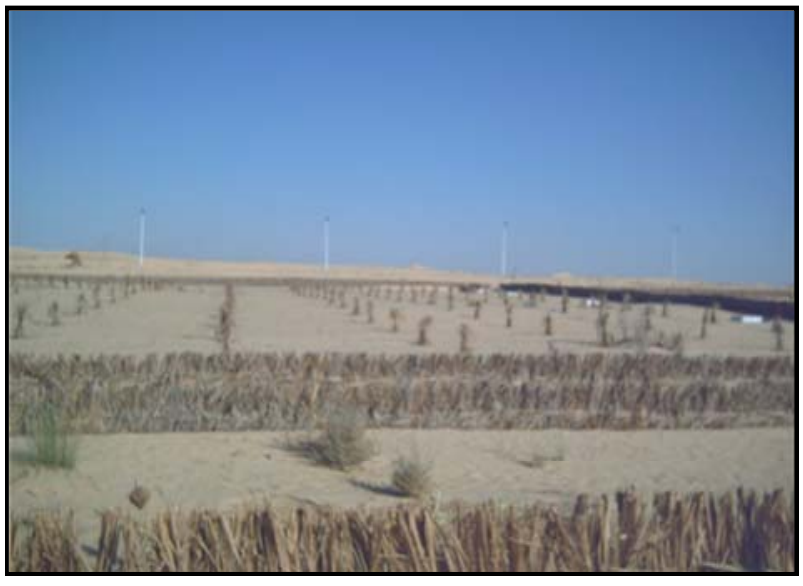

Photo 1. Implantation of olives trees around the university of El-Oued [8].

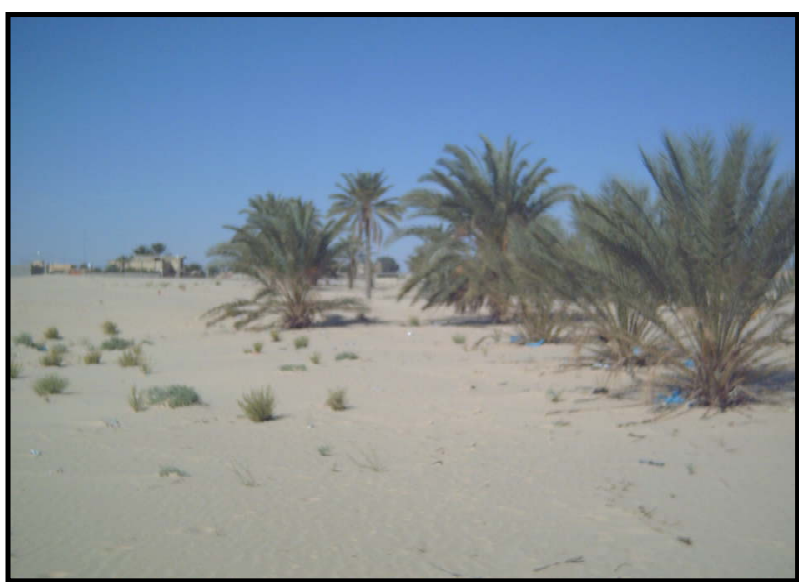

Photo 2. “Ghout” recently filled by the authorities [8].

and irrigation water in order to fight against the groundwater rising. It's a new strategy which can classify in the concept of managing risk, associated with quantitative and qualitative aspects of water resources, back to excess water [8]. A general schematic representation of this project is demonstrated in Figure 5, indicating that it is essentially based on four (04) schemes.

\subsubsection{Sanitation Scheme}

In the major municipalities of the valley (12 municipalities), the method of remediation used is collective type with a collection network of $750 \mathrm{~km}$ and 57 pumping 


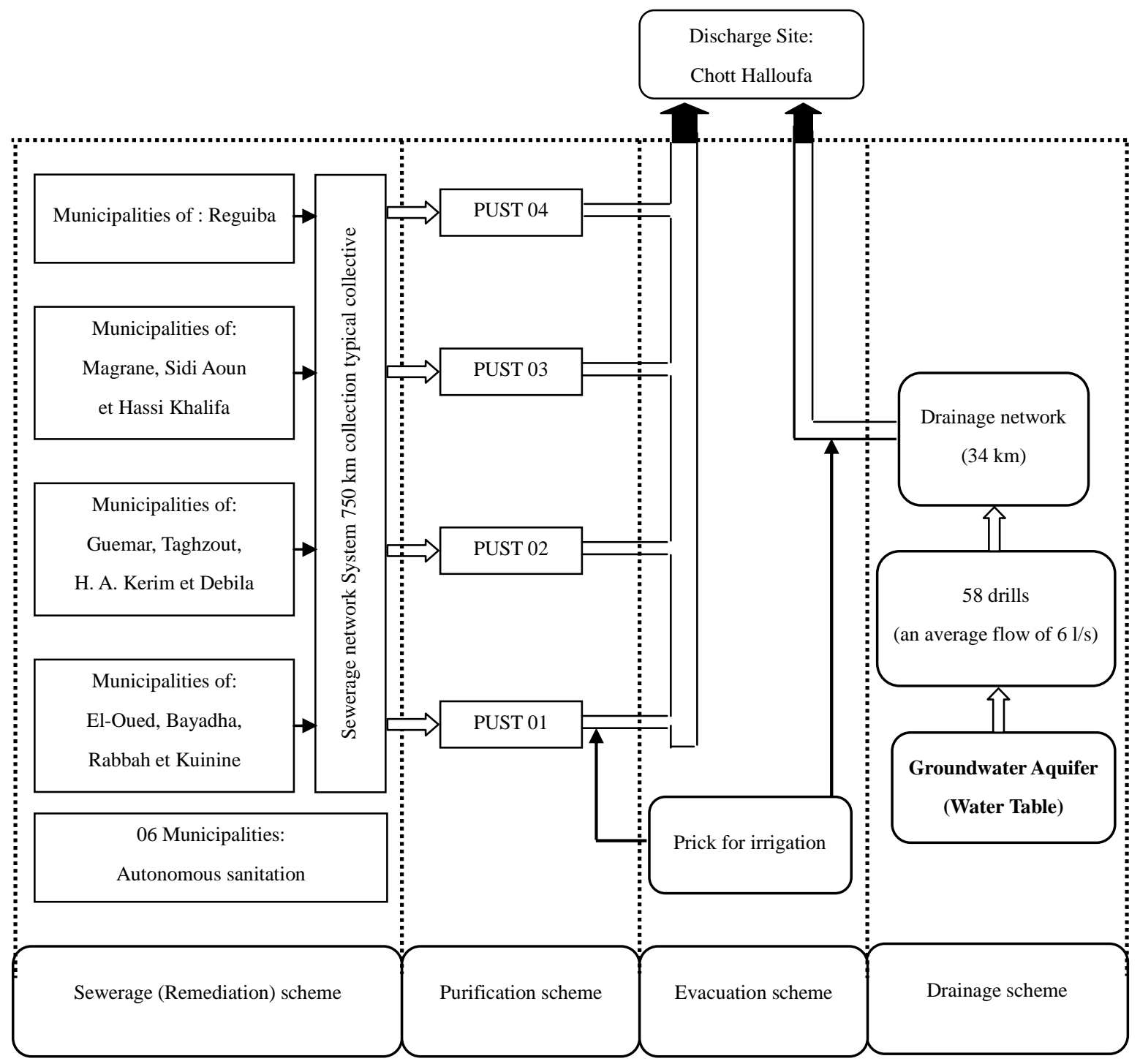

PUST: Purification Station

Figure 5. Schematic outline of the project.

stations (lift station and discharge station), in the rest of municipalities (6 municipalities), the method used is ameliorate self-sanitation.

\subsubsection{Purification Scheme}

The 12 municipalities are divided to four (04) subgroups. A purification station is proposed for each group. The purification field chosen is airy lagoon because it is respond to the aims of this project.

\subsubsection{Drainage Scheme}

In the study area, the drainage solution proposed is by the vertical drainage system, composed of a network of 58 drills (wells) connected to $34 \mathrm{~km}$ of pipes; all drainage water resulted in the pumping station already existing, which then evacuated to the final discharge site.

\subsubsection{Evacuation Scheme}

The evacuation of all treated wastewater with drainage water carried out through a transfer collector, its orientation south-north to the final discharge site, located at 70 $\mathrm{km}$ northwest of the valley.

Following each purification station, there is installing a system of capturing wastewater treated, with the possibility of reusing water for agriculture along the drainage system.

\subsection{The Expected Objectives of the New Management Policy}

The integrated management of water resources in Oued Souf valley concerns all quantitative and qualitative issues, which are interrelated, usually in competition and it can manage dependently with the socio-economic and 
eco-systems aspects. The choice of this problem (rising groundwater) is the subject of integrated management, which comes to respond population needs and the values of society. This is why; the integrated management of water resources in the valley has four (04) main objecttives.

\subsubsection{Stabilize the Level of Water Table}

When the system starts working, we will finish with the rising water and its many negative impacts, which affected several sectors, especially housing, environment and agriculture. The stabilization of the groundwater level will reduce flow fluctuations from one period to another [9].

\subsubsection{Reuse of Drainage Water in Agriculture (or Restoration of Evacuated Water)}

The taking of wastewater treated coming from the purification station, will be possible because of the implementation of pricking system along the pipeline. A sampling regulator to irrigate the green spaces is intended at the output of the local protection of each drill which is located in public places (schools, public administration). A taking (wastewater treated and drainage water) will guarantee on certain degree a supply of irrigation water, to protect at least a part of the agricultural production [10].

\subsubsection{Increase of Ground Purifying}

The space between drills was calculated as in pumping period, the water level is maintained at $4 \mathrm{~m}$ below the surface of the lowest points (Ghouts), which elevate the self-sanitation of the ground.

\subsubsection{Ecological and Healthy Maintain of Discharge Site}

The environmental evaluation and the impact study of the discharges site whose accompany this project, as well as the constraints and potential environmental on health and ecological system were identified in a perspective of sustainable development. The responsible and experts of project signed that the discharge site (named Chott of Haloufa, located northwest of Oued-Souf Valley) is maintained, and the choice of this site is appropriate and will have no negative impact whatsoever on the environment or on the salt deposits (situated at $20 \mathrm{~km}$ ), and any change in choice of this site will inevitably lead again, to the emergence of the problem of rising groundwater, but local associations and nongovernmental organizations (NGO) have been known to change this place for ecological reasons to the Oriental Erg [8].

\section{Discussion and Recommendations}

The establishment of forecast scenarios shows that the water reserves in Oued Souf valley will satisfy the needs of different users and the balance will rest excess, even in the long term (2040).

The application of this new management in Oued Souf valley is inadequate, because it can be risks of failure: the planning is not take a consider of the human being factor that may play a role very important in the implementation of this strategy, as it can be a source of troubles and conflict. On this plan, we recommend to include and take in account all actors and components of this unit of water resources (authority, local officials, citizens, NGO, farmers $\cdots$ ) who has effect on the water resource management, and this can't be, only with programming of meetings between the different actors focus in collaboration approach and avoiding central planning which emerged exclusively from studies office. In terms of agriculture, the creation of new agricultural areas irrigated by modern methods (as drop by drop) permit to reduce the danger turf of rising groundwater.

The organization of awareness and training campaigns of local citizens in: the risk of this serious problem, the risk that can lead with wastage of water especially for irrigation, the importance of integrated management and the benefits to gain from this project in various sectors, will give good results.

Finally, the project funding must be provided continuously (as energy and maintenance of equipment), at this step, we recommend that exploit the renewable energy including the solar and wind, and to involve farmers (who constitute the major beneficiaries) at a part of project funding, this by applying the principle: User/Payer. These to ensure that future generations may benefit again and this project go far in the path of sustainable development.

\section{Conclusions}

The valley of Oued-Souf suffering decades of rising groundwater and the cause's adverse effects on the habitat and the environment is located southeast of Algeria and its climate is a hyper-arid Saharan type.

The confrontation between the amount of water requested and actually provided (between 2002 and 2009) for all users allows us to conclude that the balance sheet resources-needs is a surplus and the growing requirements are offset by the volume of exploitable water.

The establishment of forecast scenarios shows that the balance will remain positive (usable volume is greater than demand) even long-term (2040). But the nature of fossil groundwater in the region raises the question of the sustainability of their operations, especially since this region is increasingly seen as an area highlighted by the water, it leaves us adapt a new strategy for managing water resources in the region that will arise more in terms of supply management in general, and irrigation effici- 
ency in particular.

The adaptation of the integrated management of water resources in the valley of Oued Souf can solve the problem of rising groundwater, and these negative impacts on different sectors and provide concrete and measurable results in socio-economic and environmental system.

\section{REFERENCES}

[1] G. George, "Integrated Management of Water Resources: Concepts and Application,” Quebec, 2004, 45 p.

[2] National Meteorological Office, "Average Daily of Precipitation and Temperature (1978/2008),” 2009.

[3] ASD (Agricultural Services Direction of El-Oued), “Canvas and Assessment (2002-2009),” 2009, 7 p.

[4] B. Bousalsal, "Contribution on Hydrogeological and Hydrochemical Study of the Phréatic Aquifer in Souf Valley,” Magister Thesis, University of Annaba, Annaba, 2007, $165 \mathrm{p}$.

[5] D. Geofiay, "Prévisions des Demandes en eau en Zone
Urbaine CIHEAM Options Méditerranéennes,” Séminaires Méditerranéens Paris, Paris, 1997.

[6] HD (Hydraulics Direction of El-Oued), "Report of Inquiry into the Holdings and Demand for Supply Water in El-Oued,” 2009, 4 p.

[7] K. Khelef, "Study of Rising Groundwater in Oued-Souf. Master Thesis School of Management EURO-MED," University of Marseille, 2006, 100 p.

[8] S. Khechana, "Study of the Integrated Management of Water Resources in the Valley of Oued-Souf (SE Algeria),” Magister Thesis, University of Annaba, 2007, 133 p.

[9] J. N. Cretenet, et al., "Valley Souf: Studies Remediation of Wastewater, Storm Water and Irrigation,” Mission IB Sanitation Scheme, 2003, 456 p.

[10] J. M. Burri and J. P. Burri, "Valley Souf: Studies Remediation of Wastewater, Storm Water and Irrigation, Additional Measures for against the Rising Water Table, Mission II,” 2004, 111 p. 